\title{
Fibulorhizoctonia psychrophila is the causal agent of lenticel spot on apple and pear fruit in the Netherlands
}

\author{
M. Wenneker • K. T. K. Pham • M. E. C. Lemmers • F. A. de Boer • P. J. van Leeuwen • \\ T. C. Hollinger • F. G. van de Geijn • B. P. H. J. Thomma
}

Accepted: 27 September 2016/Published online: 7 October 2016

(C) The Author(s) 2016. This article is published with open access at Springerlink.com

\begin{abstract}
In a survey for postharvest diseases of apples and pears in the Netherlands, an unknown postharvest fruit rot was observed. The disease appeared to originate from infected lenticels. A fungus was consistently isolated from the decayed fruits. The fungal pathogen was isolated on potato dextrose agar, and at low temperatures development of a fast-growing whitish mycelium was observed. Growth of this fungus was observed between 1 and $20^{\circ} \mathrm{C}$ with an optimum at $15^{\circ} \mathrm{C}$, while incubation of mycelium at $25^{\circ} \mathrm{C}$ resulted in no growth. The isolates did not produce asexual or sexual spores. The isolates were characterized and identified by morphology and molecular phylogenetic analysis. Genomic DNA was isolated and amplified using ITS1-ITS4, EF1 and RPB2 primers, and BLAST searches in GenBank placed the fungus taxonomically in the genus Fibulorhizoctonia, with the highest matches to F. psychrophila. Pathogenicity of representative isolates from apple and pear fruit was confirmed under laboratory conditions. To the best of our knowledge this is the
\end{abstract}

M. Wenneker $(\bowtie) \cdot$ K. T. K. Pham • M. E. C. Lemmers • F. A. de Boer · P. J. van Leeuwen · T. C. Hollinger Applied Plant Research, Wageningen University and Research, P.O. Box 200, 6670 AE Zetten, The Netherlands e-mail: marcel.wenneker@wur.nl

F. G. van de Geijn

Food \& Biobased Research, Wageningen University and Research, P.O. Box 17, 6700 AA Wageningen, The Netherlands

B. P. H. J. Thomma

Laboratory of Phytopathology, Wageningen University, P.O. Box 16, 6700 AA Wageningen, The Netherlands first report of $F$. psychrophila causing lenticel spot on apple and pear, and also the cause of a whitish mould on storage bins.

Keywords Athelia $\cdot$ Postharvest

Apple (Malus domestica) and pear (Pyrus communis) are important fruit crops in the Netherlands, with a total production of 353,000 and 349,000 tons, respectively, in 2014. The main apple and pear cultivars are Elstar and Conference, comprising 40 and $75 \%$ of the respective production areas (CBS 2016).

Fruit are stored under specific controlled atmosphere (CA) conditions for up to 11 months, depending on the cultivar and volume to be marketed. Storage conditions are always a balance between the required quality demands and prevention of physiological disorders (van Schaik and Verschoor 2003). Initially CA storage technology was restricted to standard or traditional CA storage in which $\mathrm{O}_{2}$ levels were maintained at about 2-3\%. However, improvements in gas monitoring equipment and storage room structure have resulted in the development of several additional CA-based methods to improve quality maintenance. One of these methods is Dynamic Controlled Atmosphere (DCA) storage, which maintains $\mathrm{O}_{2}$ levels below $1 \%$ for apples of cv. Elstar.

As fruit may be stored for an extended period, postharvest diseases caused by various fungal pathogens can be a limiting factor to long-term storage (Gariepy et al. 2005; Snowdon 1990). In this study, packinghouse surveys of postharvest diseases on stored apple and pear 
fruit were conducted from 2012 to 2015. Decayed apple and pear fruit were sampled from commercial packinghouses, representing orchards of various apple and pear producing areas and cultivars in the Netherlands. The aim of the study was to determine the main causal agents of postharvest diseases of apple and pear fruit in the Netherlands.

Symptoms of lenticel spot were observed on fruit of apple cv. Elstar and pear cv. Conference during these surveys. Disease incidences ranged from very low to $>25 \%$. The symptoms started as small brown to black spots $\left(1-5 \mathrm{~mm}^{2}\right)$ that originated from lenticels. The spots enlarged in a circular fashion and became sunken as the disorder progressed. The centre of the lesion was depressed, often with cracks and mycelium in the centre. One fruit could have several to many lesions. In prolonged cold storage the disease developed further, and gradually decay of the whole fruit occurred (Fig. 1a, b). In particular cases the lenticel spot was accompanied with mycelial or fungal growth on fruit and overgrowth of the (wooden) storage bins (Fig. 2a, b). The symptoms were normally expressed after a prolonged period of storage of at least 5-6 months at controlled atmosphere (CA). In previous reports from packinghouses, lenticel spot was observed, but at that time it was considered a physiological disorder and often related to DCA storage conditions (Wenneker et al. unpublished data). The experiments described were performed in order to reveal the identity of the causal agent of lenticel spots on apples and pears.

In total 7, 1,9, and 5 lots of apple fruit and 7, 0, 1, and 4 lots of pear fruit with symptoms of lenticel spot were analysed in 2012, 2013, 2014, and 2015, respectively. Mycelium samples were taken from wooden bins, with lenticel spot affected fruits, and covered with a whitish mould at three different storage locations.

Representative samples of 20 fruits were collected and used for isolation and further studies. Symptomatic fruit were transported to the laboratory, rinsed with sterile water, and sprayed with $70 \%$ ethanol until runoff.
Small pieces of the fruit flesh from the border between healthy appearing and diseased tissue were placed onto potato dextrose agar (PDA). The PDA plates were incubated at 5 and $20^{\circ} \mathrm{C}$ in the dark.

Mycelial growth on PDA of two apple isolates (44640, 44656) and one pear isolate (44747) was evaluated at different temperatures. For that, a 5-mm diameter mycelial plug from the margin of 10-day-old cultures was placed in the centre of PDA plates. Inoculated plates were incubated in the dark at 1, 5, 10, 15, 20, and $25^{\circ} \mathrm{C}$. The colony diameter was measured after 4,7 , and 11 days on each of the plates. Three replicates for each isolate were used.

The identities of a representative isolate from apple (44640) and pear (44747) were confirmed by means of multi-locus gene sequencing. Genomic DNA was extracted using the LGC Mag Plant Kit (Berlin, Germany) in combination with the Kingfisher method (Waltham, USA). The ITS1-5.8S-ITS2 region, translation elongation factor 1-alpha (EF1) and DNA-directed RNA polymerase II subunit two (RPB2) loci were amplified and sequenced. Mycelium samples taken from the whitish mould covering storage bins containing infected apple or pear fruit were sequenced directly (ITS1-5.8S-ITS2 region), as the mycelium showed no growth after placing it on PDA.

Experiments were conducted to test pathogenicity of the fungus on apple and pear fruits. Three isolates of Fibulorhizoctonia psychrophila, two from apple (44640 and 44656) and one from pear (44747) were selected. Experiments were carried out on surface-sterilized fruit. One side of the fruit was wounded using a sterile cork bore before inserting a mycelium plug (10 $\mathrm{mm}$ diameter) of actively growing mycelium of $F$. psychrophila prepared from a 7-day-old culture grown on PDA. All three isolates were tested on apple, while the isolates 44640 (from apple) and 44747 (from pear) were tested on pear. The inoculated fruit and controls treated with PDA agar plugs only, were sealed in plastic bags and incubated in the dark at $10^{\circ} \mathrm{C}$.
Fig. 1 Lenticel spot symptoms on apple cv. Elstar (a) and pear cv. Conference (b)
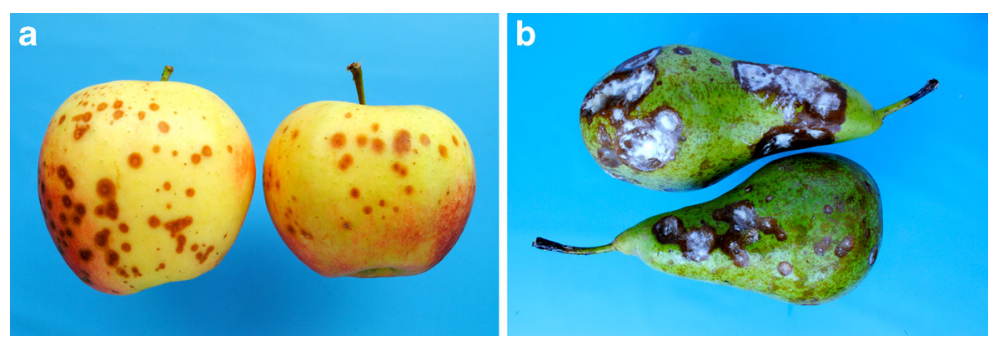
Fig. 2 A whitish mould on apples (a) and wooden storage bins (b) associated with lenticel spot
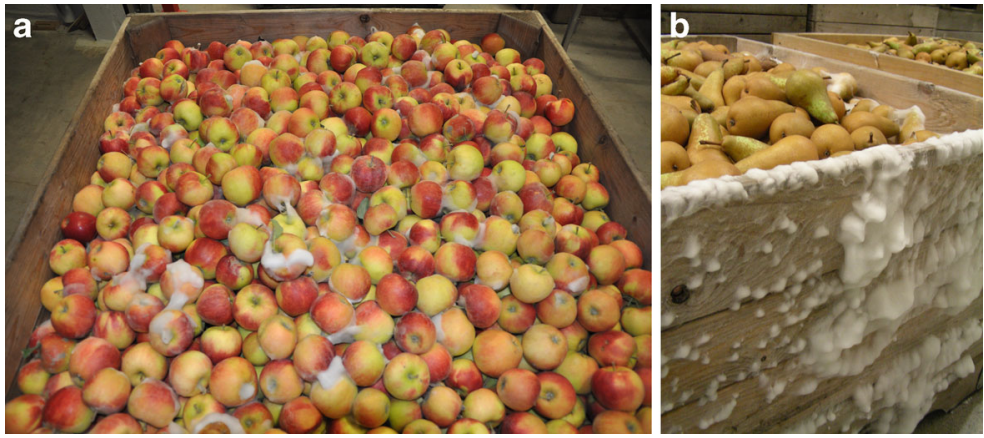

After placing the apple and pear tissue onto PDA at $5{ }^{\circ} \mathrm{C}$, white, rapidly growing colonies were observed, while incubation at $20^{\circ} \mathrm{C}$ resulted in no growth (Fig. 3). All 22 apple and 12 pear samples revealed the same fungus. Pure cultures were obtained by transfer of hyphal tips onto fresh PDA and incubating them at $5{ }^{\circ} \mathrm{C}$. Plates completely covered with the fungus were incubated at $5^{\circ}$ and $20{ }^{\circ} \mathrm{C}$ with $12 / 12 \mathrm{~h}$ photoperiod and near-UV light (Philips TL-D, 18W BLB). The isolates did not produce asexual or sexual spores. Optimal mycelial growth of the three isolates tested occurred at $15^{\circ} \mathrm{C}$, and growth was absent at $25^{\circ} \mathrm{C}$ (Fig. 4).

The sequences of the isolate from apple (44640) and pear (44747) were deposited in GenBank under accession numbers KT223398 \& KT223399 (ITS), KT962188 \& KT962189 (EF1) and KT962186 \& KT962187 (RPB2). MegaBLAST analysis revealed that the ITS sequences matched with Fibulorhizoctonia spp. (teleomorph: Athelia spp.), and more specifically with $99.3 \%$ identity to $F$. psychrophila of the reference isolate CBS: 109695 from carrot (De Vries et al.

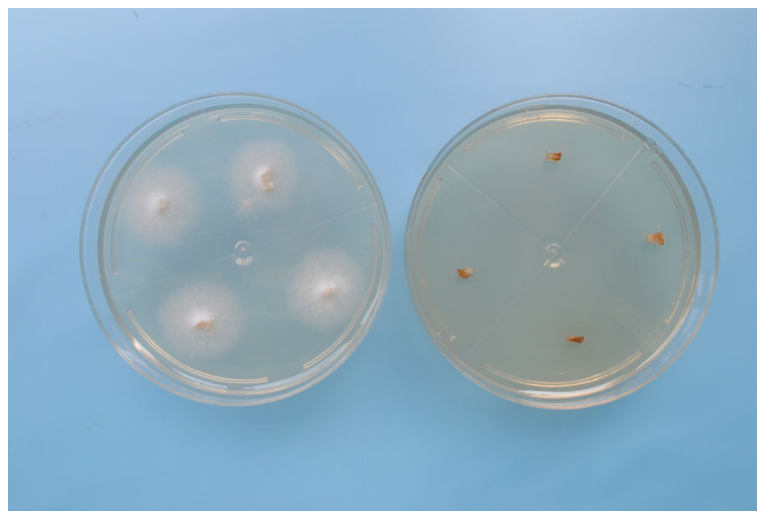

Fig. 3 Isolations of lenticel spot from apple tissue after 7 days, incubated at $5{ }^{\circ} \mathrm{C}$ (left) and $20^{\circ} \mathrm{C}$ (right)
2008), confirming the identity of the isolates as $F$. psychrophila. ITS sequencing of $F$. psychrophila revealed 97.2, 95.4, and $92.5 \%$ match to the ITS sequence of Athelia arachnoidea CBS:418.72 (GU187504), Athelia epiphylla CFMR:FP-100564 (GU187501), and Fibulorhizoctonia centrifuga CFMR 580 (U85790), respectively, indicating that $F$. psychrophila is very closely related to these three species. EF1 sequencing of F. psychrophila revealed 86.6 and $86.4 \%$ match to the EF1 sequence of $A$. arachnoidea CBS:418.72 (GU187504), and A. epiphylla CFMR:FP-100564 (GU187501), respectively. RPB2 sequencing of F. psychrophila revealed 83.4 and $82.4 \%$ match to the RPB2 sequence of $A$. arachnoidea CBS:418.72 (GU187504), and A. epiphylla CFMR:FP-100564 (GU187501), respectively. The EF1 and RPB2

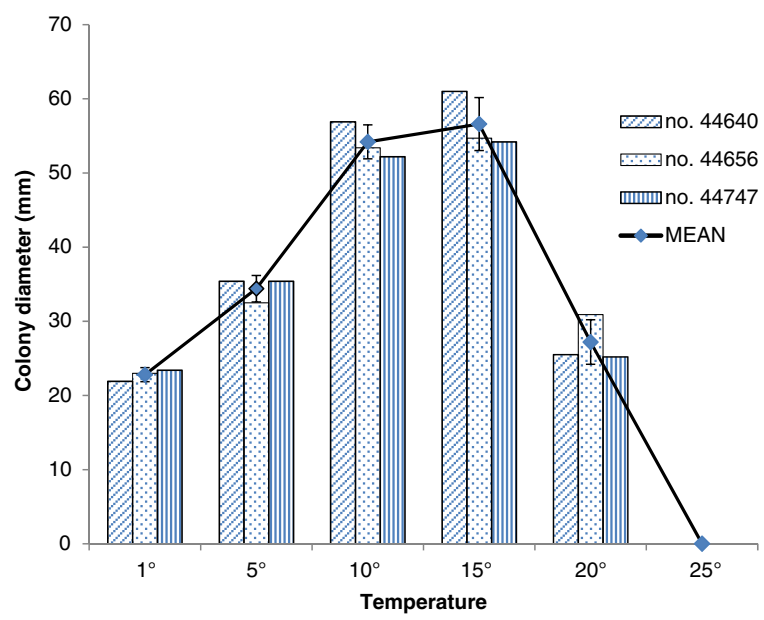

Fig. 4 Colony size of three isolates of Fibulorhizoctonia psychrophila after 11 days at different temperatures grown on potato dextrose agar (PDA). Colony diameters are the average of three PDA plates for each isolate. The mean value is the average of the nine PDA plates. Error bars indicate the standard deviation 
sequences of $F$. centrifuga CFMR 580 (U85790) were not available in GenBank. Sequencing of the whitish mould covering storage bins with lenticel spot affected apples and pears also confirmed the identity of this mould as F. psychrophila.

All apple and pear fruits inoculated with the fungus developed symptoms of decay 3 weeks after inoculation. Re-isolations from lesions consistently displayed growth and morphological characteristics identical to those previously described. ITS sequencing of the three isolates confirmed the identity of the causal agents. This indicates that apple and pear isolates of $F$. psychrophila are pathogenic to apple and pear fruit.

It may be concluded that the lenticel spot disease on apple cv. Elstar and pear cv. Conference was caused by the basidiomycete Fibulorhizoctonia psychrophila. Originally, this disease was classified as a physiological disorder, and sometimes directly related to new methods of long storage such as DCA. It is more likely that the expression of symptoms is related to the storage period, humidity and low temperatures. F. psychrophila also appears to be the whitish mould that may cause dense coverage of fruit and crates in storage. The identification of the causal agent might previously have been hampered due to the low optimal grow temperature of the fungus. It was not possible to isolate the fungus from infected apple material at $20{ }^{\circ} \mathrm{C}$ as no fungal growth occurred. The decrease in growth of $F$. psychrophila at temperatures above $15^{\circ} \mathrm{C}$ suggests a strong adaptation of this fungus to cold biotopes. Currently, lenticel spot is considered one of the most serious postharvest diseases of cv. Elstar in the Netherlands.

There are a number of basidiomycete species reported from cold stored apple and pear fruit causing so-called fisheye rot or lenticel spot. Coprinus rot in cold storage affected several apple cultivars and cv. d'Anjou pears in British Columbia and Oregon (Meheriuk and McPhee 1984; Spotts et al. 1981). The symptoms consisted of dry, dark brown lesions with tan centres, and importantly in all cases, advanced stages of decay were marked by masses of cottony, white mycelium that covered the surface of infected fruit and packing materials (Meheriuk and McPhee 1984). Eventually, the fungus was identified as a new species, Coprinus psychromorbidus (Traquair 1987). In The Netherlands, the appearance of a whitish mould in storage is often automatically associated with $C$. psychromorbidus, however the fungus was never found in our study.
Another type of fisheye rot of stored apple fruit has been reported from North America (Butler 1930; Eustace 1903), Canada (Weresub and Illman 1980), and Poland (Bielenin 1986). Eustace (1903) and Butler (1930) described the pathogenic species under the name Corticium centrifugum, which is now known as Butlerelfia eustacei (Weresub and Illman 1980). This fungus was also reported as the causal agent of fish eye rot on pear fruit in The Netherlands (Stalpers and Loerakker 1984). Butlerelfia is a fungal genus in the family Atheliaceae. Athelia species are well known as cold-tolerant spoilage fungi in other crops that are stored at low temperatures. According to Blumenfeld and Dobra (1986), A. epiphylla was isolated from pear fruit in Argentina.

Our study revealed that the isolated F. psychrophila from apple and pear fruit is closely related to the isolate of de Vries et al. (2008) that was described as a new carrot-spoilage fungus, detected in refrigerated storage facilities for carrots in The Netherlands. ITS sequencing of F. psychrophila revealed $95 \%$ identity to the ITS sequence of $A$. arachnoidea and A. carotae, indicating that $F$. psychrophila is very closely related to these two species. According to de Vries et al. (2008), the teleomorphs have not been observed in $F$. carotae and $F$. psychrophila. The optimal growth of $F$. carotae and A. arachnoidea was between 18 and $21^{\circ} \mathrm{C}$. For F. psychrophila growth was observed between 0 and $20^{\circ} \mathrm{C}$, with an optimum between 9 and $12{ }^{\circ} \mathrm{C}$, while 15 to $32{ }^{\circ} \mathrm{C}$ resulted in no growth.

Currently, information about the epidemiology, the teleomorph, infection routes, and conditions of infection of apple and pear fruit by $F$. psychrophila is lacking. In general, Athelia spp.; e.g., A. arachnoidea, A. bombacina, and A. epiphylla are described as active colonisers and decomposers of deciduous leaves and conifer needle residue, and thus their primary ecological role is as nutrient recycling agents (Adams and Kropp 1996). Apparently, at some stage these species are also able to infect apple and pear fruit. Orchard litter, such as dead roots, dead leaves and dead stems of grasses and clovers from the orchard floor, were considered as potential sources of inoculum for C. psychromorbidus in postharvest rot of apple and pear fruit stored at low temperature in British Columbia (Sholberg and Gaudet 1992). Possibly, orchard litter could also serve as a source of inoculum for lenticel spot of apples and pears. 
Acknowledgments The authors would like to acknowledge Henny Balkhoven (Fruitconsult) for providing apple and pear samples. This project was funded by the Dutch Ministry of Economic Affairs and the Dutch Horticultural Board (Productschap Tuinbouw).

Open Access This article is distributed under the terms of the Creative Commons Attribution 4.0 International License (http:// creativecommons.org/licenses/by/4.0/), which permits unrestricted use, distribution, and reproduction in any medium, provided you give appropriate credit to the original author(s) and the source, provide a link to the Creative Commons license, and indicate if changes were made.

\section{References}

Adams, C., \& Kropp, R. (1996). Athelia arachnoidea, the sexual state of Rhizoctonia carotae, a pathogen of carrot in cold storage. Mycologia, 88, 459-472.

Bielenin, A. (1986). Apple rot caused by Corticium centrifugum (Lév.) Bres. in storage. Fruit Science Reports, 13, 143-147.

Blumenfeld, S. N., \& Dobra, A. (1986). Athelia epiphylla pers. (Aphyllophorales, Corticeaceae), agente causal del ojo de pescado en peras conservadas en cámara frigorífica. Actas de las VI Jornadas Fitosanitarias Argentinas. Fitopatología, 2, 335-343.

Butler, L. F. (1930). Corticium centrifugum, a heterothallic pathogene of apples. Journal of Agricultural Research, 41, 269-294.

CBS. (2016). Statistics Netherlands. http://www.cbs.nl/enGB/menu/home/default.htm. Accessed 30 Mar 2016.

De Vries, R. P., De Lange, E. S., Wösten, H. A. B., \& Stalpers, J. A. (2008). Control and possible applications of a novel carrot-spoilage basidiomycete, Fibulorhizoctonia psychrophila. Antonie van Leeuwenhoek, 93, 407-413.
Eustace, H. J. (1903). Two decays of stored apples. I. Another apple rot following scab. New York State Agricultural Experiment Station, Bulletin, 235, 123-129.

Gariepy, T. D., Rahe, J. E., Lévesque, C. A., Spotts, R. A., Sugar, D. L., \& Henriquez, J. L. (2005). Neofabraea species associated with bull's-eye rot and cankers of apple and pear in the Pacific Northwest. Canadian Journal of Plant Pathology, 27, 118-124.

Meheriuk, M., \& McPhee, W. J. (1984). Postharvest handling of pome fruits, soft fruits, and grapes (Agriculture Canada, Publication 1768E). Ottawa: Research Branch.

Sholberg, P. L., \& Gaudet, D. A. (1992). Grass as a source of inoculum for rot caused by Coprinus psychromorbidus in stored apples. Canadian Journal of Plant Pathology, 14, 221-226.

Snowdon, A. L. (1990). A colour Atlas of post-harvest diseases and disorders of fruits and vegetables. Vol. 1: General introduction and fruits. Boca Raton: CRC Press.

Spotts, R. A., Traquair, J. A., \& Peters, B. B. (1981). D'Anjou pear decay caused by a low temperature basidiomycete. Plant Disease, 65, 151-153.

Stalpers, J. A., \& Loerakker, W. (1984). Over Butlerelfia eustacei (visseoogziekte) en Auriculariopsis ampla. Coolia, 27, 74-81.

Traquair, J. A. (1987). Postharvest rot by Coprinus psychromorbidus on apples and pears in cold storage in British Columbia. Canadian Plant Disease Survey, 67, 47-50.

Van Schaik, A. \& Verschoor, J. (2003). CA-storage: technology, application and research. State of the art in the Netherlands. ISHS Acta Horticulturae 600. VIII International Controlled Atmosphere Research Conference, 181-187.

Weresub, L. K., \& Illman, W. I. (1980). Corticium centrifugum reisolated from fisheye rot of stored apples. Canadian Journal of Botany, 58, 137-146. 